\title{
Long-term follow-up of glycaemic control and parameters of lipid transport after pancreas transplantation
}

\author{
H. Drexel ${ }^{1}$, G. Palos ${ }^{1}$, A. Königsrainer ${ }^{2}$, G. Miesenböck ${ }^{1}$, C. Aichberger ${ }^{2}$, R. Margreiter $^{2}$ and J. R. Patsch $^{1}$ \\ ${ }^{1}$ Division of Clinical Atherosclerosis Research, Department of Medicine, and ${ }^{2}$ Department of Transplant Surgery, \\ University of Innsbruck, Austria
}

\begin{abstract}
Summary. We report the long-term metabolic observations made on 37 patients after simultaneous pancreas and kidney transplantation. Plasma C-peptide levels were above the physiological range in all patients and there was no significant difference between patients undergoing delayed duct occlusion $(n=12)$ or those with drainage of exocrine secretion into the urinary bladder $(n=25) . \mathrm{HbA}_{1 \mathrm{c}}$ was equally at the upper end of the normal range in both subsets of patients. Mean fasting cholesterol $(237 \mathrm{mg} / \mathrm{dl})$ and triglycerides $(122 \mathrm{mg} / \mathrm{dl})$ were normal, and HDL-cholesterol was above normal with an average concentration of $77 \mathrm{mg} / \mathrm{dl}$. Two patients underwent an oral fat tolerance test and showed extremely low postprandial lipaemia and very high lipoprotein lipase activities. We conclude that patients with a functioning pancreas graft persistently demonstrate normoglycaemia, elevated Cpeptide, and a very favourable lipid profile both in the fasting and the postprandial state.
\end{abstract}

Key words: Pancreas transplantation - Glycaemic indices - Plasma C-Peptide - Lipids - Lipoproteins

\section{Introduction}

Successful pancreas transplantation is at present the only possibility to achieve long-term normoglycaemia and insulin-independence in patients with Type 1 (insulindependent) diabetes mellitus (Robertson et al. 1989). However, the procedure is accompanied by peripheral hyperinsulinaemia because the pancreatic venous blood is drained into the systemic circulation rather than into the portal vein (Robertson et al. 1989).

Peripheral (and portal) hyperinsulinaemia are common features of obesity and Type 2 (non-insulin-dependent) diabetes mellitus and are often associated with hypertriglyceridaemia, low HDL-cholesterol, and hypertension (Reaven 1988). In this study, we investigated the long-term effects of pancreas transplantation on plasma C-peptide and glycaemic indices. In addition, we studied lipid and lipoprotein parameters in those patients with primary peripheral hyperinsulinaemia.

\section{Subjects and methods}

Patients. In 37 patients with Type 1 diabetes and end-stage diabetic nephropathy, a simultaneous pancreas/kidney transplantation (SPK) was performed, whereby the exocrine pancreatic tissue was either destroyed by delayed duct occlusion (DDO) using an alcoholic prolamine solution $(n=12)$ or pancreas secretion was drained into the bladder $(B D, n=25)$. Details of the surgical procedure and the protocol of follow-up are given in a foregoing article of this volume (Königsrainer et al.). In three patients of each group, graft failure occurred. These six patients were evaluated together. Table 1 summarizes the means (ranges) of the demographic data of the patients with persistent graft function of both kidney and pancreas.

Table 1. Demographic data of patients with persistent graft function

\begin{tabular}{lcc}
\hline & DDO & BD \\
\hline & & \\
n & 9 & 22 \\
sex (female/male) & $7 / 2$ & $6 / 16$ \\
age (years) & $40(19-56)$ & $36(27-59)$ \\
diabetes duration (years) & $21(13-30)$ & $24(3-37)$ \\
height $(\mathrm{cm})$ & $164(155-175)$ & $170(160-195)$ \\
weight $(\mathrm{kg})$ & $59(50-70)$ & $61(45-74)$ \\
& & \\
\hline
\end{tabular}

$\mathrm{DDO}=$ delayed duct occlusion; $\mathrm{BD}=$ bladder drainage

Serum creatinine averaged $1.3 \mathrm{mg} / \mathrm{dl}$ (range $0.7-2.3$ ) in DDO patients and $1.4 \mathrm{mg} / \mathrm{dl}$ (range $0.8-2.4$ ) in BD patients one year after transplantation. The creatinine levels after two years were $1.5 \mathrm{mg} / \mathrm{dl}(1.1-2.5)$ in DDO and $1.2(1.0-1.5)$ in BD patients.

At monthly intervals, percentage of $\mathrm{HbA}_{1 \mathrm{c}}$ and a diumal blood glucose profile were determined. Beginning at 21 months after SPK in DDO patients and at 3 months after SPK in BD patients, cholesterol, triglycerides, and HDL-cholesterol were measured every 4 months; Cpeptide was determined every 4 months in all patients at $2 \mathrm{~h}$ after the subject's usual breakfast in order to obtain a dynamic index of insulin secretion. 
For prophylactic immunosuppression, all patients received a triple-drug regimen including cyclosporine $A$ using a priming dose of 3 mg.day $^{-1}$ $\mathrm{kg}^{-1}$ body weight, with subsequent dosage adjustment to plasma levels between 150 and $200 \mathrm{ng} / \mathrm{ml}$; azathioprine $1.5 \mathrm{mg} \cdot \mathrm{day}^{-1} \cdot \mathrm{kg}^{-1}$ body weight; and prednisone $10 \mathrm{mg} / \mathrm{day}$.

Analytical procedures. All assays were performed in duplicate on a Cobas Mira Autoanalyzer (Roche, Basle, Switzerland). Cholesterol and triglycerides were determined by an automated enzymatic method, details of which have been described elsewhere (Drexel et al. 1988). For measurement of HDL-cholesterol, a dextrane-sulphate precipitation method (Wamick et al. 1982) was used.

Plasma C-peptide was measured by radioimmunoassay (RIA-mat, CPeptide II, Byk-Sangtec Diagnostica, Dietzenbach, Gemany); the normal range is $0.17-0.99 \mathrm{pmol} / \mathrm{ml}$. $\mathrm{HbA}$, c was determined by a microcolumn method (Quick-Sep, Isolab, Oh., USA; normal range 4.2$5.9 \%$ ) and blood glucose by an automated hexokinase method. A standardized oral fat tolerance test was performed in two patients as described in detail previously (Patsch et al. 1983). Lipoprotein lipase and hepatic lipase activities were measured at $25^{\circ} \mathrm{C}$ in post-heparin plasma using specific antisera (Peterson et al. 1985); mean $+/-1$ SD in 50 healthy probands was $287+1-71$ and $604+1-139 \mathrm{nmol}^{\text {NEPA.ml }}{ }^{-1}$. $\min ^{-1}$, respectively.

Statistical analysis. Normal range was defined as the mean plus/minus the $2 \mathrm{SD}$ interval.

\section{Results}

\section{Plasma C-peptide}

Figure 1 illustrates $\mathrm{C}$-peptide levels which were above the normal range in all patients with continuous graft function after DDO or BD. In the six patients with graft failure, C-peptide decreased towards the lower end of the normal range around one year after SPK.

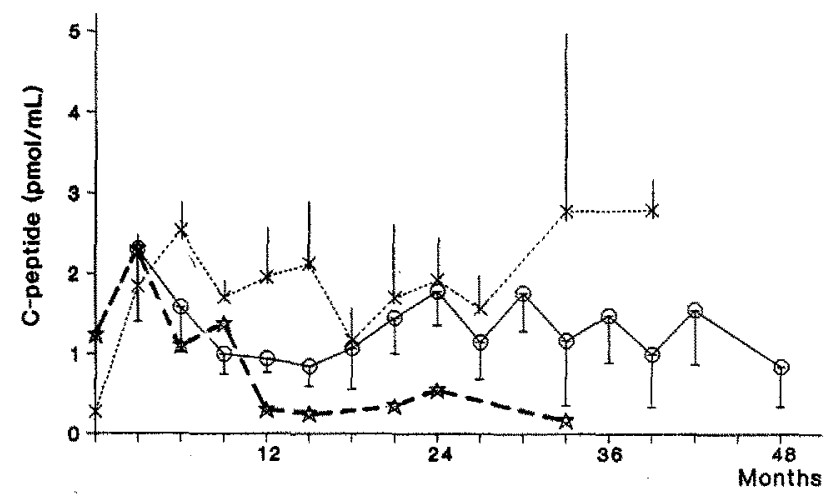

Fig.1. Postprandial plasma C-peptide concentrations . Delayed duct occlusion (DDO): $\mathrm{o}$, solid line; bladder drainage (BD): $\mathrm{x}$, dotted line; $\mathrm{DDO}$ and $\mathrm{BD}$ patients are described in Table 1 ; insulin requiring patients: $*$, broken line

\section{Glycaemic indices}

Both mean blood glucose and $\mathrm{HbA}_{1 \mathrm{c}}$ were persistently at the upper end of the normal range. As can be seen from Figure 2, the values for DDO and BD were almost superimposable such that there was no significant difference between the two groups.
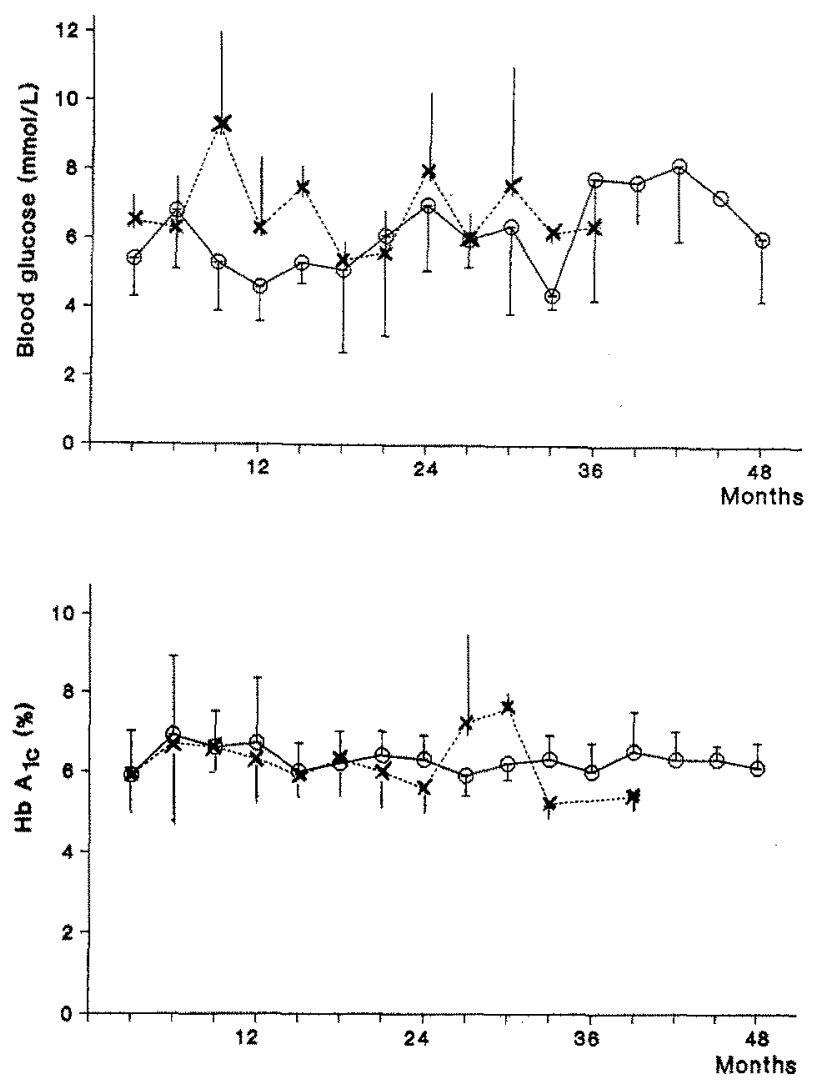

Fig.2. Long-term follow-up of mean blood glucose (upper panel) and $\mathrm{HbA}_{1}$ \& (lower panel). Delayed duct occlusion: $\mathrm{o}$, solid line; bladder drainage: $x$, broken line

\section{Fasting lipids}

In both groups of patients, triglycerides were always within the normal range with a mean (SD) of $128(63)$ and 111 (47) mg/dl, respectively. Cholesterol (Fig. 3) was 230 (32) $\mathrm{mg} / \mathrm{dl}$ after BD and 241 (33) after DDO; HDLcholesterol was 87 (14) $\mathrm{mg} / \mathrm{dl}$ and 68 (15), respectively. In all three parameters, the two groups showed no significant difference and the mean of all measurements from all patients were: cholesterol 237 , triglycerides 122 , and HDL-cholesterol $77 \mathrm{mg} / \mathrm{dl}$.

\section{Postprandial lipaemia}

Two patients underwent the standardized oral fat tolerance test. As shown in Figure 4, the postprandial triglyceride response is extremely low. Postheparin lipoprotein lipase activities were 600 and $711 \mathrm{nmol}$ NEFA. $\mathrm{ml}^{-1} \cdot \mathrm{min}^{-1}$, i.e. above the $95^{\text {th }}$ percentile. Hepatic lipase activities were 185 and 312 nmol NEFA. $\mathrm{ml}^{-1} \cdot \mathrm{min}^{-1}$, i. e. below the $5^{\text {th }}$ percentile. 

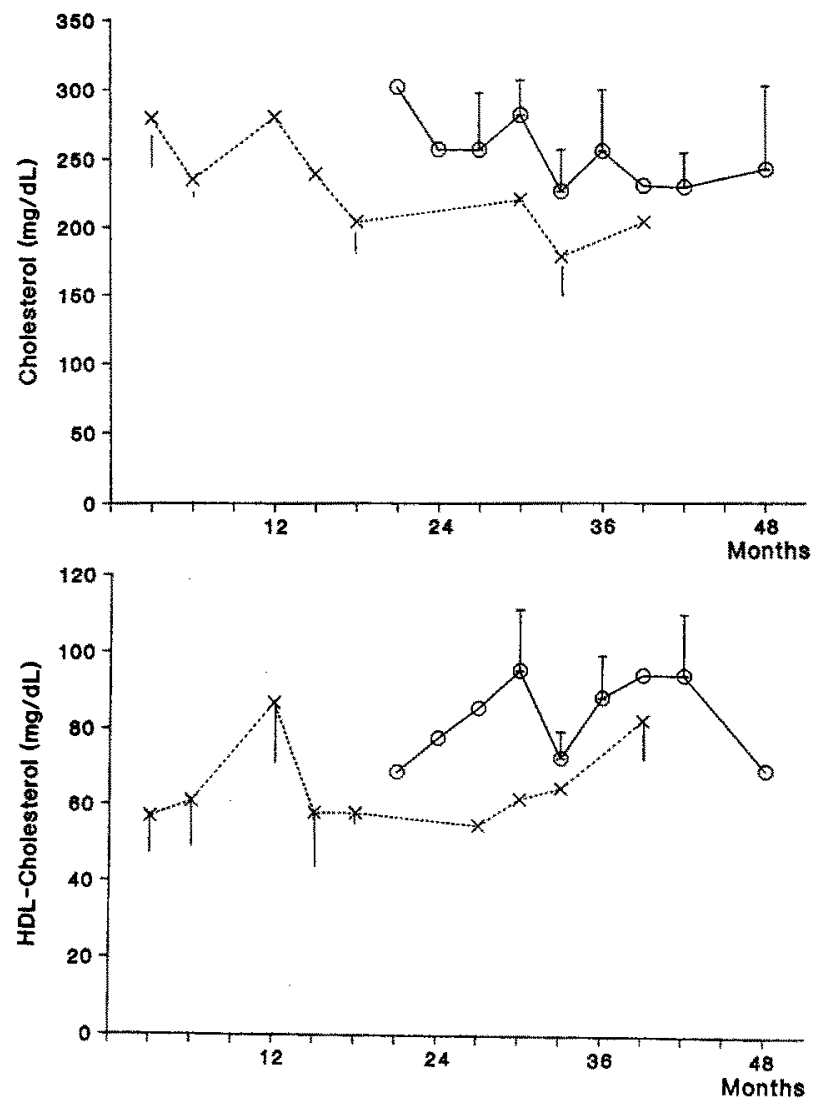

Fig.3. Long-term follow-up of total plasma cholesterol (upper panel) and HDL-cholesterol (lower panel). Delayed duct occlusion: 0 , solid line; bladder drainage: $x$, dotted line

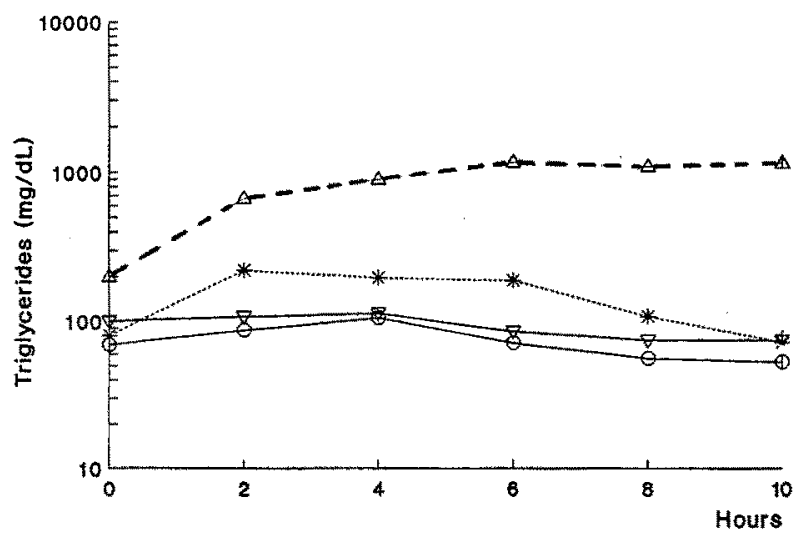

Fig.4. Postprandial triglyceride response in two patients after SPK ( $v, 0$, solid lines). For comparison, the response of a normal proband $\left(^{*}\right.$, dotted line) and of a patient with Type 2 (non-insulin-dependent) diabetes mellitus ( , broken line) are also depicted

\section{Discussion}

This study was designed to determine the long-term effect of different surgical techniques for SPK, i.e. DDO and $\mathrm{BD}$, on C-peptide levels, glycaemic indices, and plasma lipids. In none of the parameters investigated, was there a significant difference between the two techniques suggesting that both afford a very similar functional capacity of the graft. These findings agree with the data of Tyden et al. (1989) who found no differences in fasting blood glucose, glycosylated haemoglobin, and intravenous glucose tolerance for up to 3 years.

With respect to glycaemic parameters, it should be pointed out that, although normoglycaemic, $\mathrm{HbA}_{10}$ was at the upper end of normal. It has been argued that this level of control may not be completely satisfactory, e.g. in pregnancy (Mills et al. 1988), to completely prevent complications.

We found a favourable pattem of lipids and especially of HDL-cholesterol after SPK in both groups. The preliminary data on postprandial fat tolerance are in line with the findings in fasting lipids and indicate a very efficient postprandial triglyceride clearance. Increased activity of lipoprotein lipase, as determined in the two patients, can be explained by peripheral hyperinsulinaemia, because insulin is a potent stimulator of the enzyme. Therefore, primary hyperinsulinaemia as a resuit of SPK confers a very favourable lipid profile that contrasts sharpiy with that seen in obese non-diabetic and Type 2 diabetic patients with hyperinsulinaemia, i.e. hypertriglyceridaemia and low HDL-cholesterol. The important difference between the two hyperinsulinaemic states appears to be the fact that, in obesity and Type 2 diabetes, hyperinsulinaemia exists not only in the systemic but also in the portal vascular bed and is probably a result of insulin resistance and, thus, secondary. This suggests to us that hyperinsulinaemia per se does not induce hypertriglyceridaemia in vivo.

Acknowledgements. We thank Mr. H. Fetz for assistance in preparation of the manuscript, and Mrs. Ch. Comploy, Mrs. I. Hauser, Mrs. I. Pritz, Miss J. Rössler, and Miss G. Tröbinger for technical assistance. This work was supported by grant HL 27341 from the National Institute of Health and by grant S 46/06 from the Austrian "Fonds zur Förderung der wissenschaftlichen Forschung".

\section{References}

Drexel H, Hopferwieser Th, Braunsteiner H, Patsch JR (1988) Effects of biosynthetic human proinsulin on plasma lipids in Type 2 diabetes mellitus. Klin Wschr 66:1171-1174

Mills J,, Knopp RH, Simpson J, Jovanovic-Peterson L, Metzger BE, Holmes LB, Aarons JH, Brown Z, Reed GF, Bieber FR, Van Allen M, Holzman I, Ober C, Peterson CM, Withiam MJ, Duckles A, MuellerHeubach E, Polk BF, and the National Institute of Child Health and Human Development Diabetes in Early Pregnancy Study (1988) Lack of relation of increased malformation rates in infanls of diabetic mothers to glycemic control during organogenesis. N Engl J Med 318:671-676

Patsch JR, Karlin JB, Scott LW, Smith LC, Gotto AM, Jr (1983) Inverse relationship between blood levels of high density lipoprotein subfraction 2 and magnitude of postprandial lipemia. Proc Natl Acad Sci USA 80:1449-1453 
Peterson J, Olivecrona T, Bengtsson-Olivecrona G (1985) Distribution of lipoprotein lipase and hepatic lipase between plasma and tissues: effect of hypertriglyceridemia. Biochim Biophys Acta 837:262-270

Reaven GM (1988) Role of insulin resistance in human disease. Diabetes 37:1595-1607

Robertson RP, Abid M, Sutherland DER, Diem P (1989) Glucose homeostasis and insulin secretion in human recipients of pancreas transplantation. Diabetes 38, Suppl 1:97-9

Tyden G, Brattström C, Bolinder J, Bohman S-O, Groth C-G, Brekke IB, Holdaas H, Flatmark A (1989) Long-term metabolic control in recipients of segmental-pancreas grafts with pancreaticoenterostomy or duct obstruction. Diabetes 38, Suppl 1:94-96

Warnick GR, Benderson J, Albers JJ (1982) Dextran sulfate- $\mathrm{Mg}^{2+}$ precipitation procedure for quantitation of high-density-lipoprotein cholesterol. Clin Chem 28:1379-1388

Dr. Heinz Drexel

Medizinische Klinik - Kardiologie

Departement für Innere Medizin

Rämistraße 100

CH-8091 Zürich

Switzerland 